\title{
FLEXURAL REINFORCED CONCRETE ELEMENTS NORMAL SECTION BEARING CAPACITY EVALUATION IN FRACTURE STAGE
}

\author{
Justas SLAITAS ${ }^{\mathrm{a}}$, Zbynek HLAVAC ${ }^{\mathrm{b}}$, Arnoldas ŠNEIDERIS ${ }^{\mathrm{a}}$ \\ ${ }^{a}$ Vilnius Gediminas Technical University, Sauletekio al. 11, LT-10223 Vilnius, Lithuania \\ ${ }^{b}$ Research Centre Rez Ltd., Morseova 4 Borska pole, 30100 Plzen, Czech Republic
}

Received 27 October 2016; accepted 30 March 2017

\begin{abstract}
This article examines flexural reinforced concrete structures condition assessment process in existing buildings on the stage where the reinforcement stress is between the yield and the tensile strength. The research is made on V. Jokübaitis proposed methodology directly measuring the compression zone height, allowing us to evaluate the behavior of reinforced concrete beam fracture sufficiently precisely. This paper confirms the hypothesis that, when reinforcement reaches yielding stress, elastic strain dominates in concrete's compression zone and it is reasonable to use triangular concrete compression zone diagram, without tensile concrete above crack evaluation. The methodology of reinforced concrete structures bearing capacity assessment according to limit normal section crack depth is proposed. There is established connection between bending moments, when reinforcement achieve yielding stress and tensile strength, which allows us to decide about structures bearing capacity reserve. The results are confirmed with experimental studies and calculated values obtained by methodologies based on different reduced stress diagrams of concrete's compressive zone.
\end{abstract}

Keywords: reinforced concrete, flexural strength, concrete fracture, crack depth.

\section{Introduction}

Normal section fracture of flexed reinforced concrete structures starts with the reinforcement reaches the yielding stress. The fracture of the structure occurs when its concrete compressive strength reserve is fully exploited. The fracture of the reinforced concrete beams and slabs process length depends on the physical and mechanical properties of concrete and reinforcement. Therefore, in normal section strength analytical and experimental studies of reinforced concrete beams attention is paid to the concrete compressive stress and strain interdependence and the character of the stress diagram in cross-section.

The science of fracture mechanics allows us to analyze the start of flexed reinforced concrete beams fracture by critical parameters of normal cracks, which are the consequence of stress state (when the reinforcement reached yielding stress).

This article examines flexural reinforced concrete structures condition assessment in existing buildings on the stage where the reinforcement stress is between the yield and the tensile strength (see Fig. 1).

The reinforced concrete elements normal section flexural strength is evaluated through V. Jokūbaitis proposed methodology, based on the fracture mechanics of solids (Jokūbaitis et al. 2013; Jokūbaitis, Juknevičius 2013). Results of beams flexural strength estimated values are compared with the experimental, as well as with the calculated values obtained by methodologies based on different reduced stress diagrams of concrete's compressive zone, a focus is made on a critical normal section crack's depth effect evaluation.

Corresponding author:

J. Slaitas E-mail: justas.slaitas@vgtu.lt 

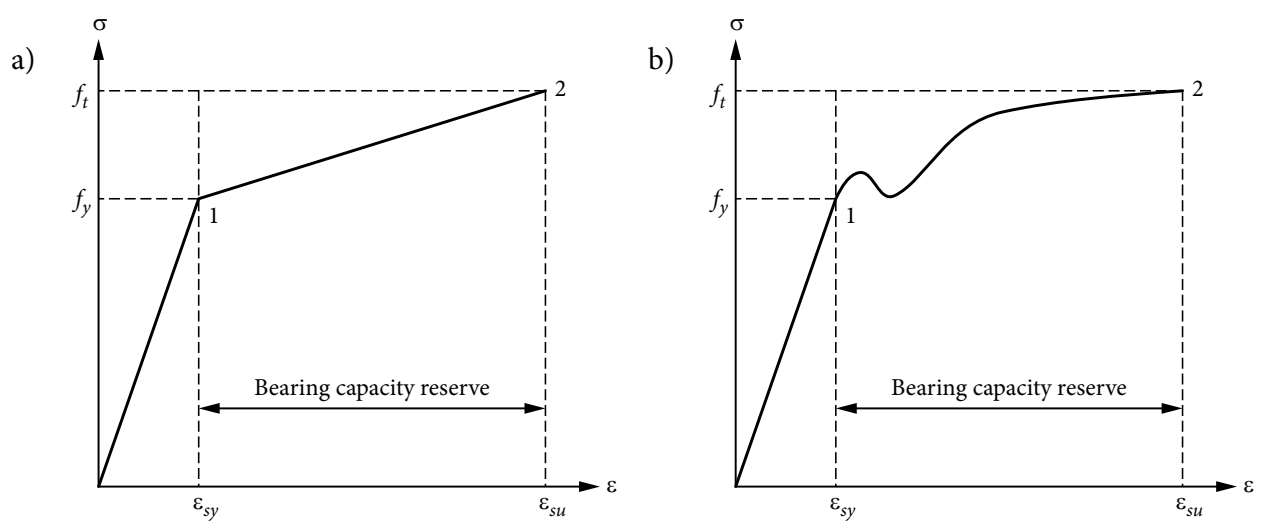

Fig. 1. The examined stage of reinforcement stress: a - bilinear hardening material model; $\mathrm{b}$ - steel stress-strain curve (Atkočiūnas, Čižas 2009)

\section{Reinforced concrete elements flexural strength}

In this chapter we will describe reinforced concrete elements flexural strength computing methods based on concrete's compressive zone different reduced stress diagrams and then we will go through methodology based on fracture mechanics of solids.

\subsection{Reinforced concrete elements flexural strength calculation, estimating concrete compressive stress and strain characteristics}

The reinforced concrete element's flexural strength is usually determined when curved concrete compressive zone stress diagram is replaced by the rectangular equivalent. General equations for rectangular crosssection:

$$
\left\{\begin{array}{c}
\eta \cdot f_{c m} \cdot b \cdot \lambda \cdot x=f_{y} \cdot A_{s 1}-\sigma_{s 2} \cdot A_{s 2} \\
M_{u 1}=\eta \cdot f_{c m} \cdot b \cdot \lambda \cdot x \cdot\left(d-\frac{\lambda \cdot x}{2}\right)+ \\
\sigma_{s 2} \cdot A_{s 2}\left(d-d_{2}\right)
\end{array}\right.
$$

Here: $\eta$ - reduction coefficient of concrete's compressive strength; $f_{c m}$ - concrete's compressive strength; $b$ - width of the beam; $\lambda$ - reduction coefficient of concrete's compression zone height; $x$ - concrete's compression zone height; $f_{y}$ - yield strength of tensile reinforcement; $A_{s 1}$ - area of tensile reinforcement; $\sigma_{s 2}$ - stress of compressive reinforcement; $A_{s 2}$ - area of compressive reinforcement; $d$ - effective depth of cross section; $d_{2}$ - depth of compressive reinforcement.

When the curved concrete compression zone diagram is replaced by rectangular equivalent, compression zone height and compressive strength of concrete reduction coefficients are used. According to EC2 (LST EN 1992-1-1:2005; Narayanan, Beeby 2005) $\eta_{E C 2}=1$,
$\lambda_{E C 2}=0.8$, when characteristic compressive strength of concrete $f_{c k} \leq 50 \mathrm{MPa}$. There are many methods for determination of different concrete compression zone reduction coefficients.

Coefficients $\lambda, \eta$ can be determined (Dulinskas, Zabulionis 2007; Dulinskas et al. 2007; Zabulionis, Dulinskas 2008):

$$
\begin{aligned}
& \eta_{D}=A_{c}^{2} / 2 S_{c} ; \\
& \lambda_{D}=2 S_{c} / A_{c} .
\end{aligned}
$$

Here: $A_{c}$ - the compression zone resultant; $S_{c}-$ compressive zone resultant moment around the most compressed concrete layer, calculated according to the ratio of concrete deformation at the limit stress point and concrete deformation of the most deformed compressive layer.

The proposed method of H. Rüsch (Rüsch 1960), when $2 \leq \varepsilon_{c u} \leq 3.5 \%$ :

$$
\begin{gathered}
\eta_{R} \lambda_{R}=\frac{3 \varepsilon_{c u}-2}{3 \varepsilon_{c u}} ; \\
0.5 \lambda_{R}=\frac{\varepsilon_{c u}\left(3 \varepsilon_{c u}-4\right)+2}{2 \varepsilon_{c u}\left(3 \varepsilon_{c u}-2\right)} .
\end{gathered}
$$

According to ACI 318 flexural strength of reinforced concrete beams can be set (Shafigh et al. 2011; Park, Paulay 1975):

$$
M_{u 1 . A C I}=A_{s 1} f_{y}\left(d-0.59 \frac{A_{s 1} f_{y}}{f_{c m} b}\right) .
$$

The methodology proposed above is based on concrete curvilinear stress diagram reduction to rectangular, but there are others, such as I. Židonis proposed alternative curvilinear concrete stress diagram applied to the universal stress calculation method (see Fig. 2). 


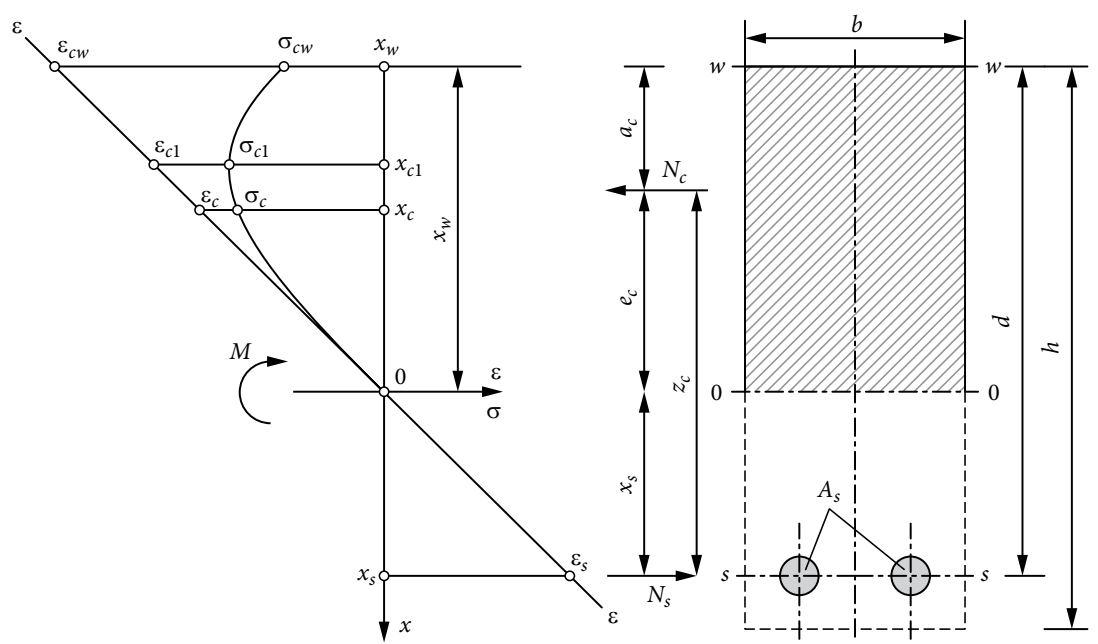

Fig. 2. The forces acting on flexed element cross-section (Židonis 2007a)

Equations to solve (Židonis 2007a, 2007b, 2010):

$$
\left\{\begin{array}{c}
\omega_{n c} \varepsilon_{c u} E_{c m} b d \xi_{w}-f_{y} A_{s 1}+\sigma_{s 2} A_{s 2}=0, \\
M_{u 1 . Z}=\omega_{n c} \varepsilon_{c u} E_{c m} b d \xi_{w}\left[1-\left(1-\frac{\omega_{m c}}{\omega_{n c}}\right) \xi_{w}\right] d+ \\
\sigma_{s 2} A_{s 2}\left(d-d_{2}\right) .
\end{array}\right.
$$

Here parameters of nonlinear stress diagram:

$\omega_{n c}=\frac{1}{2}+\frac{c_{1}}{3} \eta_{c}+\frac{c_{2}}{4} \eta_{c}^{2} ; \omega_{m c}=\frac{1}{3}+\frac{c_{1}}{4} \eta_{c}+\frac{c_{2}}{5} \eta_{c}^{2} ;$

$\xi_{w}=\frac{x_{w}}{d} ; \eta_{c}=\frac{\varepsilon_{c u}}{\varepsilon_{c 1}} ; c_{1}=3 v_{c 1}-2 ; c_{2}=1-2 v_{c 1} ;$

$v_{c 1}=\frac{f_{c m}}{1.05 E_{c m} \cdot \varepsilon_{c 1}}$.

\subsection{Reinforced concrete elements flexural strength} calculation, evaluating critical normal cross-section crack depth

Flexed reinforced concrete element's crack has two peaks, one leads to the crack spread toward the beam neutral axis, and the other refers to the tensile reinforcement, crack apex closer to the neutral axis opening width is critical to giving rise to further crack spread, for what resists concrete and steel bond strength, equal to the tensile strength of concrete $f_{c t}$ and reinforcement stress $\sigma_{s}$. Parts of the element separated by the crack rotates on a crack surface and neutral axis intersection point (Jokūbaitis et al. 2013) (see Fig. 3).

Flexed reinforced concrete element concrete's tensile zone over the crack influence is relatively small, so we take $h_{c t}=0$. Then reinforcement stresses for nonprestressed flexural RC elements (Fig. 3):

$$
\sigma_{s} \cong\left(\frac{0.59 M h_{c r}}{I_{1}^{*}}\right)\left(\frac{h_{c r}}{t}\right)^{1 / 2} \alpha .
$$

There: $M$ and $h_{c r}$ - acting bending moment and a maximum crack depth. $\alpha$ - reinforcement and concrete modulus of elasticity ratio and it could be described as a corrective function (Jokūbaitis et al. 2013); $I_{1}^{*}$ - estimated moment of inertia of rectangular crosssection on the crack zone; $t$ - equivalent cross-section height of tensile reinforcement.

Calculated reinforcement stress shows the condition of the building's in exploitation flexed reinforced concrete structure, so we can judge whether further exploitation can be operated, or we can increase the load, or it is in a critical condition.

Flexural reinforced concrete element's strength can be calculated:

$$
M_{u 1 . J} \cong\left(\frac{f_{y} I_{1}^{*}}{0.59 \alpha h_{c r, \lim }}\right)\left(\frac{t}{h_{c r, \lim }}\right)^{1 / 2} .
$$

Here $h_{c r, l i m}$ - limit crack depth.

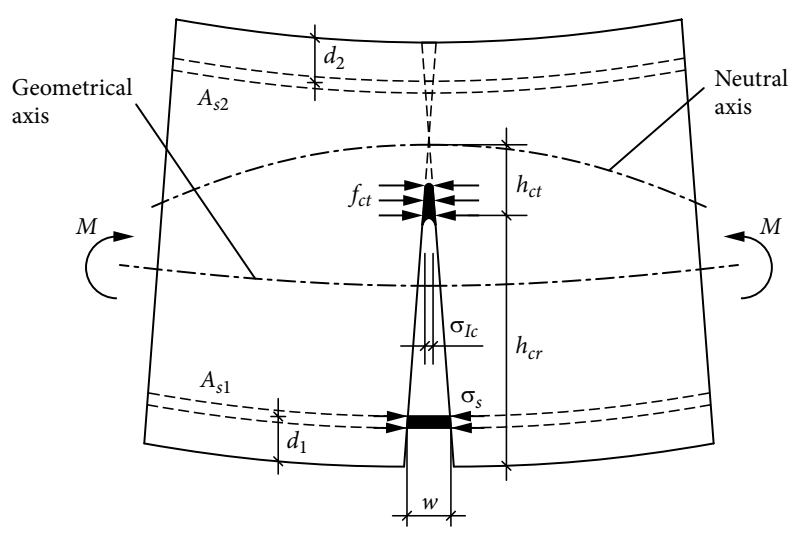

Fig. 3. The model for calculation of normal crack development (Jokūbaitis, Juknevičius 2013) 
When reinforcement stress is close to the yield strength, flexed element's compressive area strength, especially in lightly reinforced elements, are untapped. Therefore, triangular concrete compression zone stress diagram is acceptable at this condition. In this case, when tensile concrete above crack is disregarded, increases flexural strength of the beam.

This increase of flexural strength is reduced due to the compressive concrete plastic deformation and disregarding of compressive reinforcement. In accordance to provisions, the reinforced concrete beam's flexural strength from the equilibrium conditions of external and internal forces (Fig. 4) (Jokūbaitis et al. 2013):

$$
M_{u 1 . t r i} \cong \frac{f_{y} A_{s 1}\left(h_{c r, \lim }+2 h-3 d_{1}\right)}{3} .
$$

Just before the construction collapse, the concrete's compressive zone stress diagram becomes similar to rectangular, so knowing the final crack depth, we can determine the final fracture moment of the concrete according to the scheme in Figure 5.

According to Figure 5 we get the final fraction moment $M_{\text {u2.rec }}$.

$$
M_{u 2 . r e c}=\max \left\{\begin{array}{l}
f_{c m} \cdot b \cdot \lambda\left(h-h_{c r \text { max }}\right)\left(d-\frac{\lambda\left(h-h_{c r . \max }\right)}{2}\right)+ \\
A_{s 2} \cdot \sigma_{s 2}\left(d-d_{2}\right) ; \\
f_{t} \cdot A_{s 1}\left(d-\frac{\lambda\left(h-h_{c r \text { max }}\right)}{2}\right) .
\end{array}\right.
$$

There $\lambda$ - reduction coefficient of concrete's compression zone height, we take $\lambda=0.8$.

As we see from Figure 4 and Figure $5, F_{1} z_{1}<F_{2} z_{2}$, $M_{u 1}<M_{u 2}$, so when the reinforcement reaches the yielding stress beam does not collapse. The increase of bending moment from the moment when reinforcement reached yielding stress can be determined according to the equation proposed by NIIZHB laboratory (Michailov 1977):

$$
M_{u 2 . N}=M_{u 1 . o b s}\left(1.1-0.1 \frac{\xi_{y}}{\xi_{R}}\right),
$$

where: $M_{u 1 . o b s}$ - experimentally set bending moment, when tensile reinforcement reached yielding stress; $\xi_{y}$ - relative compression zone height, when tensile reinforcement reached yielding stress; $\xi_{R}$ - relative compression zone height, when reinforcement reached the tensile strength.

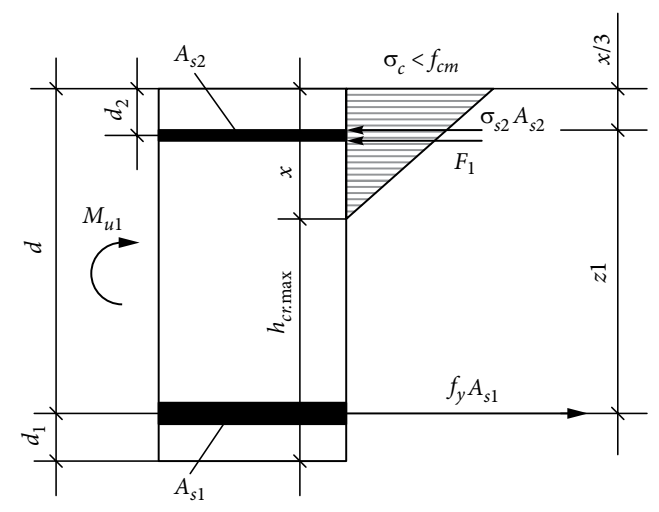

Fig. 4. Estimated state of stress when tensile reinforcement reaches yielding stress

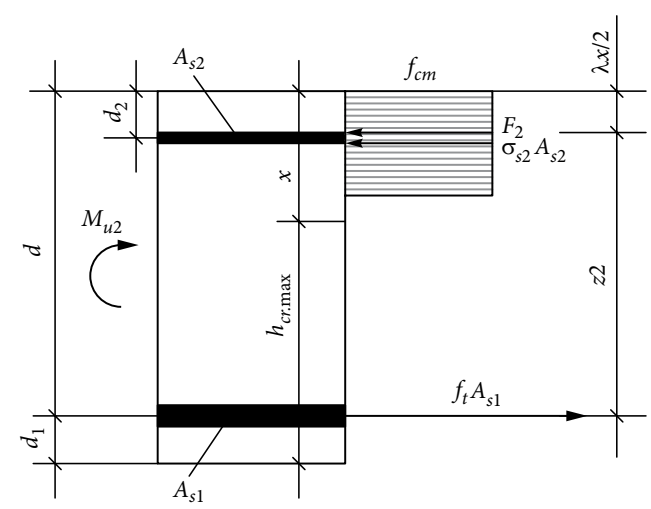

Fig. 5. Estimated state of stress just before construction collapse

\section{Experimental research}

During research 6 reinforced concrete beams were experimentally tested, 3 of them were reinforced with $2 \varnothing 12$ bars (S1-1, S1-2, S1-3) and $3-2 \varnothing 8$ bars (S2-1, S2-2, S2-3). The reinforcement layout of tested beams is given in Figure 6.

The beams were loaded with two concentrated forces (Fig. 7).

Concrete and reinforcement parameters, set from testing results of the standard samples, are presented in Table 1.

The medium deformation of tensile reinforcement was measured with $200 \mathrm{~mm}$ base electromechanical indicator and elongation on crack location - with $50 \mathrm{~mm}$ base electromechanical indicator, which had been fixed on the beams concrete (Fig. 8). At the same mid-section of the beam concrete's compressive deformation was measured with strain gauges. Firstly, beams were loaded with about $0.2 M_{u 2}$ load, till the first cracks had shown. After beams were unloaded and measuring instruments were set beside the biggest crack. Crack depth and width were measured with 

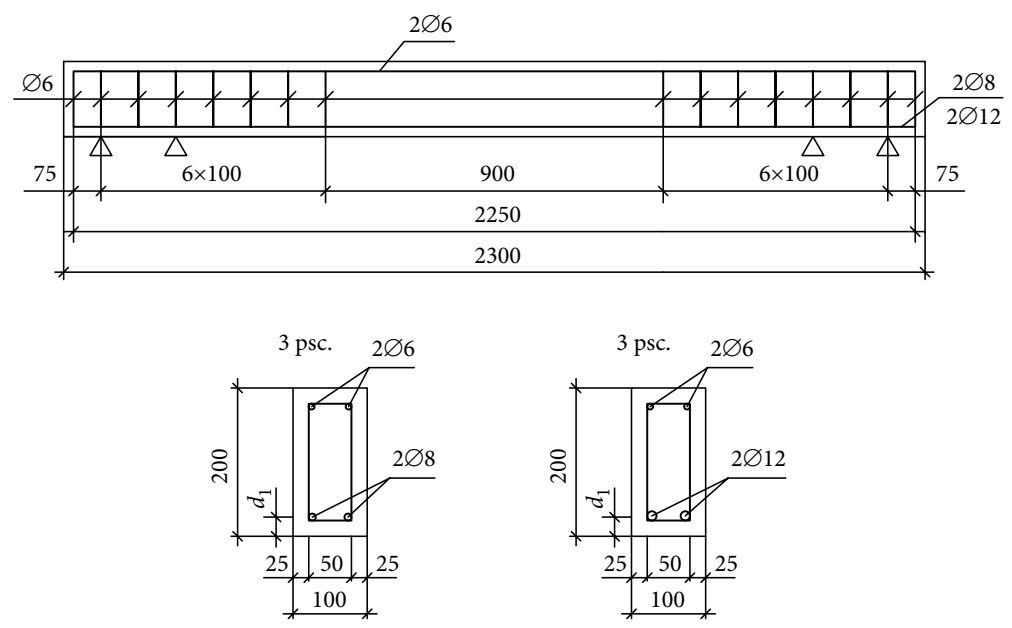

Fig. 6. The reinforcement layout of tested beams

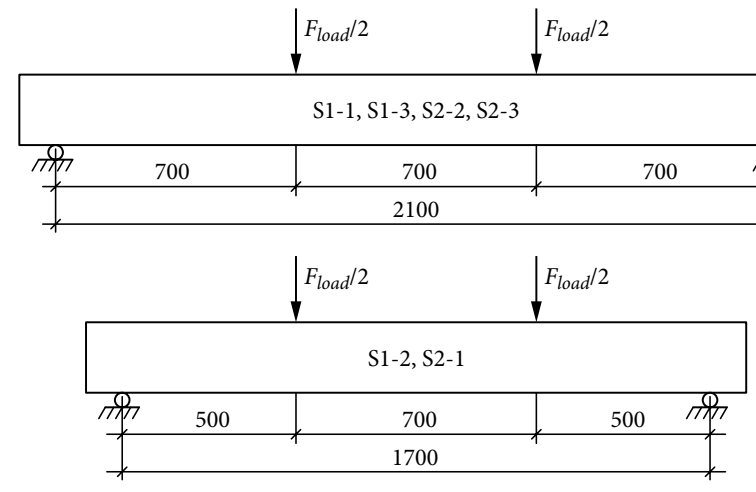

Fig. 7. The loading scheme of tested beams

Table 1. Concrete and reinforcement parameters

\begin{tabular}{|c|c|c|c|c|c|c|c|}
\hline Beam & $\rho_{s 1}, \%$ & $\begin{array}{c}f_{y,} \\
\mathrm{MPa}\end{array}$ & $\begin{array}{c}f_{t,} \\
\mathrm{MPa}\end{array}$ & $\begin{array}{c}d_{1} \\
\mathrm{~mm}\end{array}$ & $\begin{array}{c}E_{s} \\
\mathrm{GPa}\end{array}$ & $\begin{array}{l}f_{c m}, \\
\mathrm{MPa}\end{array}$ & $\begin{array}{l}E_{c m}, \\
\mathrm{GPa}\end{array}$ \\
\hline S1-1 & \multirow{3}{*}{1.3} & \multirow{3}{*}{613.3} & \multirow{3}{*}{725.1} & 26 & \multirow{3}{*}{185.6} & \multirow{6}{*}{31.6} & \multirow{6}{*}{31.1} \\
\hline S1-2 & & & & 25 & & & \\
\hline S1-3 & & & & 26 & & & \\
\hline S2-1 & \multirow{3}{*}{0.58} & \multirow{3}{*}{569.4} & \multirow{3}{*}{639.7} & 24 & \multirow{3}{*}{198.3} & & \\
\hline S2-2 & & & & 24 & & & \\
\hline S2-3 & & & & 25 & & & \\
\hline
\end{tabular}

microscope enlarging 24 times. In the initial stage of concrete cracking load step was about $0.15 M_{u 2}$, and approaching to the reinforcement yielding stress the load step was reduced to $0.075 M_{u 2}$. The load cycle duration was about $10-15$ min.

Strains at the crack location measured on a $50 \mathrm{~mm}$ base can be considered as the tensile reinforcement deformations in a crack with sufficient accuracy. Reduction of this deformations due to tensile concrete work, when hypothesis of plane sections is valid, is too small to be considered in. a)

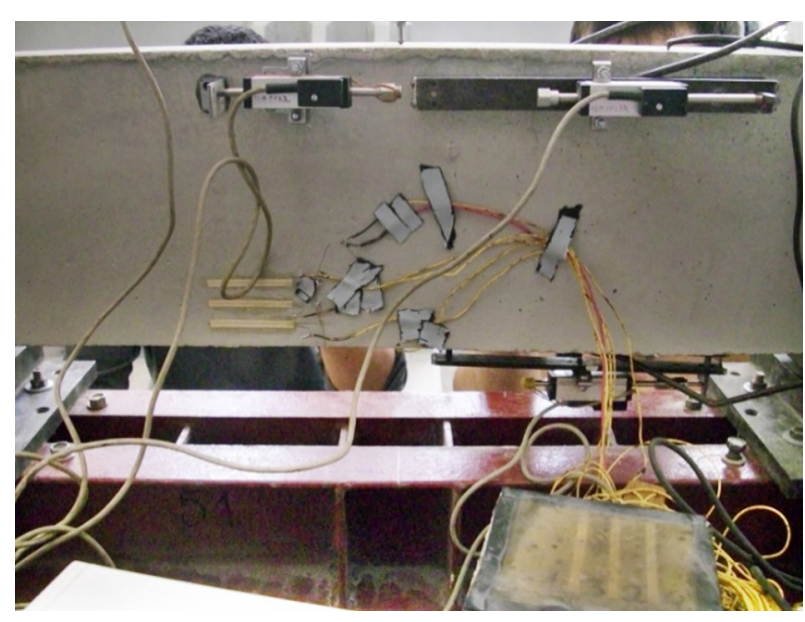

b)

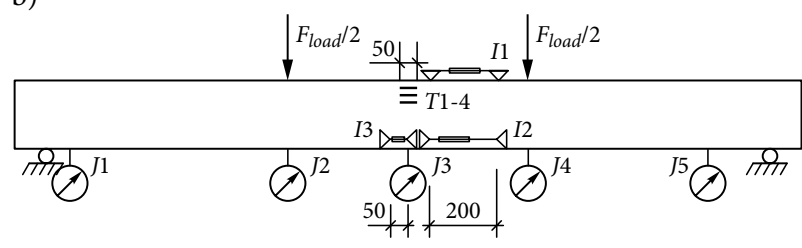

Fig. 8. General layout of the measuring instruments: a) picture (upside down); b) scheme: I1-I3, J1-J5 - electromechanical indicators; T1-T4 - strain gauges

The measured elongation of $50 \mathrm{~mm}$ section is approximately equal to the width of the crack in reinforcement level. With the strain-bending moments dependency graphs according to strain growth it was simple to determine bending moment $M_{u 1 . o b s}$, when the reinforcement stress reaches the yield strength. The bending moment $M_{u 2 . o b s}$ was set when the beam completely collapsed.

The experimental results are given in Table 2. 
Table 2. Experimental results

\begin{tabular}{|c|c|c|c|c|c|c|c|c|c|c|}
\hline Beam & $\begin{array}{c}M_{u 1 . o b s}, \\
\mathrm{kNm}\end{array}$ & $\begin{array}{l}M_{u 1 . . o b s}, \\
\text { average, } \\
\text { kNm }\end{array}$ & $\begin{array}{c}M_{u 1.0 b s}, \\
\text { variation, } \\
\%\end{array}$ & $\begin{array}{c}M_{u 2 . o b s}, \\
\mathrm{kNm}\end{array}$ & $\begin{array}{l}M_{u 2 . o b s}, \\
\text { average, } \\
\text { kNm }\end{array}$ & $\begin{array}{c}M_{u 2 . . o b s} s \\
\text { variation, } \\
\%\end{array}$ & $\underset{\mathrm{m}}{\mathrm{h}_{\text {cr.lim.obs }}}$ & $\begin{array}{c}h_{\text {crlim.obs }} \\
\text { average, } \\
\text { m }\end{array}$ & $\begin{array}{c}h_{c r l i m . o b s} \\
\text { variation, } \\
\%\end{array}$ & $\underset{\mathrm{m}}{\mathrm{h}_{\text {cr.max.obs }}}$ \\
\hline S1-1 & 22.8 & \multirow{3}{*}{23.70} & \multirow{3}{*}{2.94} & 24.9 & \multirow{3}{*}{25.37} & \multirow{3}{*}{1.45} & 0.138 & \multirow{3}{*}{0.141} & \multirow{3}{*}{1.34} & \multirow{3}{*}{0.150} \\
\hline S1-2 & 23.8 & & & 25.4 & & & 0.142 & & & \\
\hline S1-3 & 24.5 & & & 25.8 & & & 0.142 & & & \\
\hline S2-1 & 11.0 & \multirow{3}{*}{11.17} & \multirow{3}{*}{1.12} & 12.5 & \multirow{3}{*}{12.63} & \multirow{3}{*}{0.75} & 0.150 & \multirow{3}{*}{0.151} & \multirow{3}{*}{1.95} & \multirow{3}{*}{0.176} \\
\hline S2-2 & 11.3 & & & 12.7 & & & 0.155 & & & \\
\hline S2-3 & 11.2 & & & 12.7 & & & 0.148 & & & \\
\hline
\end{tabular}

As we see from Table 2, there is bearing capacity reserve of flexed reinforced concrete beams in stage where the reinforcement stress is between the yield and the tensile strength. The reserve between beam's tensile reinforcement yielding stress and final fracture got higher from $7 \%$ to $13 \%$, when decreasing the reinforcement ratio from 0.013 to 0.0058 . Such a difference was caused by beam's fracture consequence. Concrete crushed and reinforcement tensile strength was not reached when reinforcement ratio was $1.3 \%$. But when reinforcement ratio changed to $0.58 \%$ tensile reinforcement failed, it means that the full reinforcement stress reserve capacity (from yield to tensile strength) was employed.

Furthermore, limit crack depths were evaluated. The crack depth was $h_{\text {cr.lim.obs }}$, when the reinforcement stress reached the yield strength and the crack depth was $h_{c r \text { max.obs }}$, when concrete crushed or tensile reinforcement failed.

\section{Analysis of the results}

Calculated and experimental flexural strength of the beams are presented in Figure 9. There we can see the ratio of flexural strength calculated by equations (110) and experimentally set bending moment $M_{u 1 . o b s}$, when the reinforcement stress reached yield strength (see Fig. 9a). The flexural strengths are calculated by: V. Jokūbaitis (Jokūbaitis et al. 2013) proposed methodologies $M_{u 1 . J}(9)$; triangular stress diagram using directly measured concrete compressive zone's height $M_{u 1 . t r i}$ (10); EC2 methodology $-M_{u 1 . E C 2}$ (1); Dulinskas et al. (Dulinskas, Zabulionis 2007; Dulinskas et al. 2007; Zabulionis, Dulinskas 2008) $-M_{u 1 . D}(2-3)$; Rüsch (Rüsch 1960) $-M_{u 1 . R}(4-5) ;$ ACI $318-M_{u 1 . A C I}$ (6); Židonis (Židonis 2007a, 2007b, 2010) - $M_{u 1 . Z}$ (7). In Figure $9 \mathrm{~b}$ we can see the ratio between moments calculated by Eq. $(11,12)$ and experimentally set final fracture moment $M_{u 2 . o b s}$.

As we see from Figure 9a fracture strengths calculated by eq. (1-10) agree to observed bending moment, when reinforcement stress reached yield strength. Dulinskas et al. (Dulinskas, Zabulionis 2007; Dulinskas et al. 2007; Zabulionis, Dulinskas 2008) proposed methodology was the closest to experimental results. Other calculated values were lower. The ratio of calculated and experimental results became approximately $10 \%$ lower when reinforcement ratio changed from $1.3 \%$ to $0.58 \%$. Furthermore, final fracture moment calculated by eq. (11) exactly corresponds to observed, the difference is only $0 \div 1 \%$ (see Fig. $9 \mathrm{~b}$ ). The reserve of structure bearing capacity calculated by eq. (12) was about 2 times lower than reserve of experimental result. If the first member of eq. (12) would not be 1.1, but e.g. $1.13 \div 1.16$, then equality $M_{u 2 . o b s}=M_{u 2 . N}$ would be valid.

The results of reinforced concrete beams flexural strength calculation according to the EC2, ACI 318, $\mathrm{H}$. Rüsch (Rüsch 1960), I. Židonis (Židonis 2007a, 2007b, 2010), V. Jokūbaitis (Jokūbaitis et al. 2013) methodologies are similar. This means that the distance between inner forces and concrete compressive zone's resultant is similar when using triangular and curved or rectangular equivalent concrete compressive zone diagrams (see Fig. 10).

The assumption that it is possible to apply a triangular concrete compressive zone diagram, when tensile reinforcement stress is close to the yield strength, was confirmed. So we can equate the internal forces in Figure 10 and from equilibrium conditions we will have:

$$
\begin{gathered}
F_{2}=A_{s 1} f_{y}-A_{s 2} \sigma_{s 2} \\
\left(A_{s 1} f_{y}-A_{s 2} \sigma_{s 2}\right) z_{2} \approx A_{s 1} f_{y} \frac{\left(h_{c r . \lim }+2 h-3 d_{1}\right)}{3} .
\end{gathered}
$$


a)
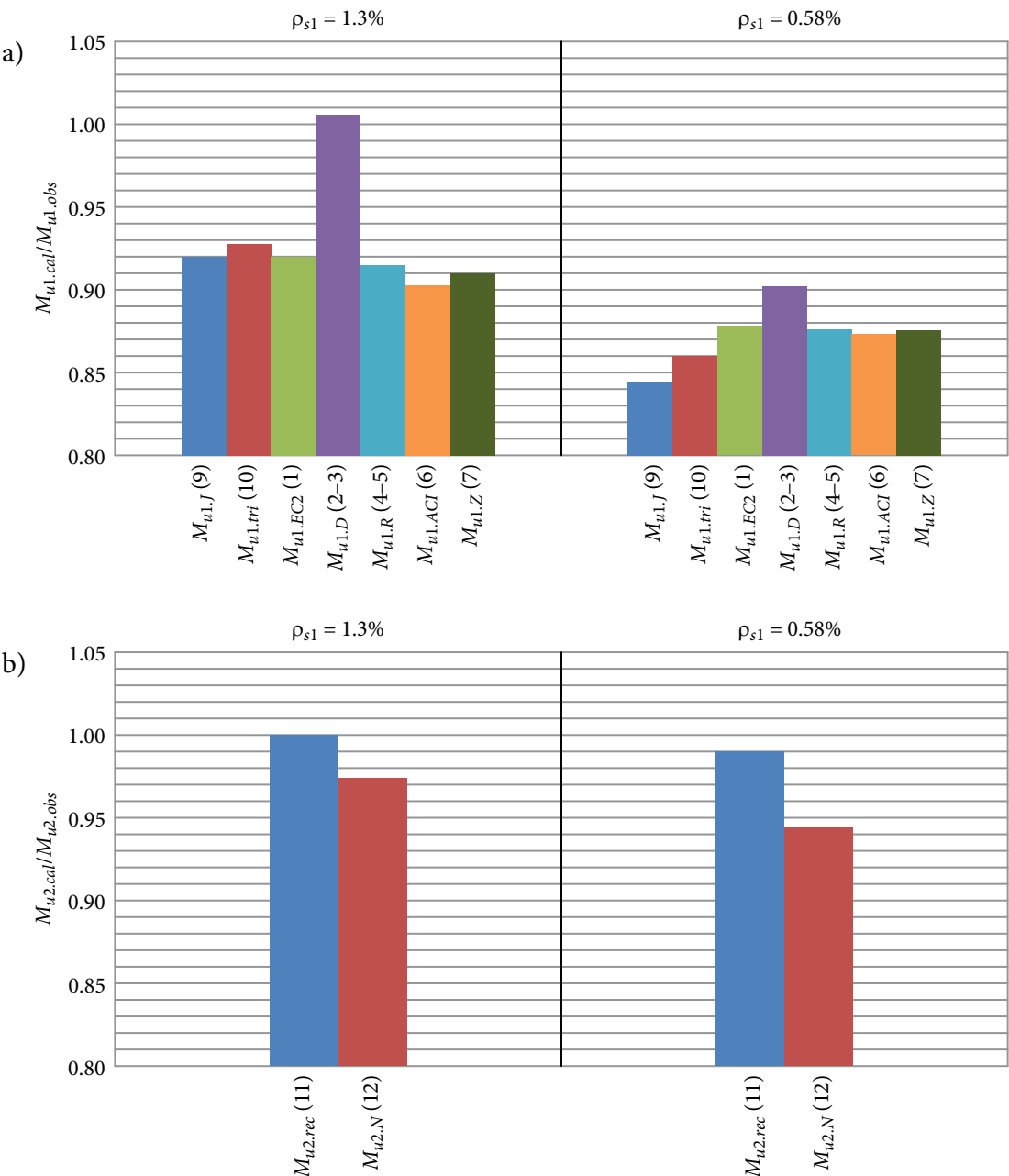

Fig. 9. a) The ratio of flexural strength calculated by equations (1-10) and experimentally set bending moment $M_{u 1 . o b s}$, when reinforcement stress reached yield strength; b) The ratio between moments calculated by eq. $(11,12)$ and experimentally set final fracture moment $M_{u 2 . o b s}$

a)

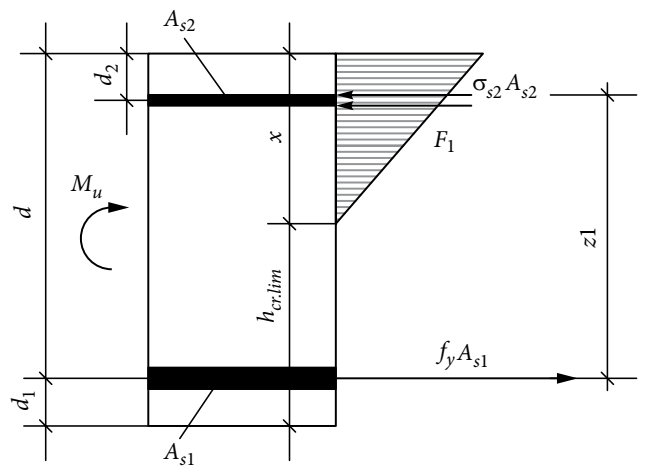

b)

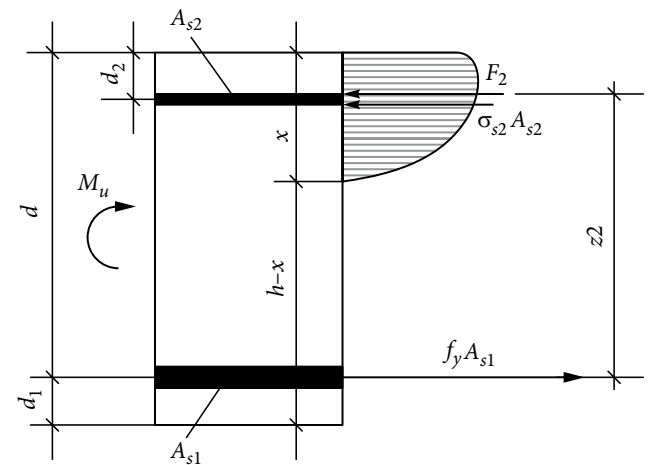

Fig. 10. Internal forces: a) using triangular concrete compressive zone stress diagram; b) using curved concrete compressive zone stress diagram

From (14) we can express the limit crack depth:

$$
h_{c r . \lim } \approx \frac{\left(A_{s 1} f_{y}-A_{s 2} \sigma_{s 2}\right) 3 z_{2}}{A_{s 1} f_{y}}-2 h+3 d_{1} .
$$

In equation (15) the relation between limit crack depth and distance between inner forces is evaluated.
The distance between inner forces can be determined by one of discussed curved or an equivalent concrete compression zone charting techniques. If there is no compressed reinforcement or we do not take it into account:

$$
h_{c r . \lim } \approx 3 z_{2}-2 h+3 d_{1} \text {. }
$$


According to (16) we can calculate the limit crack depth by applying EC2:

$$
\begin{aligned}
& h_{c r . \lim . d 1} \approx 3 h-3 d_{1}-3 \frac{A_{s 1} f_{y}}{2 \eta f_{c m} b}- \\
& 2 h+3 d_{1}=h-3 \frac{A_{s 1} f_{y}}{2 \eta f_{c m} b} .
\end{aligned}
$$

By evaluating the compressive reinforcement, according to (15) we get:

$$
h_{c r . \lim . d 2} \approx h-3 \frac{\left(A_{s 1} f_{y}-A_{s 2} \sigma_{s 2}\right)^{2}}{2 \eta f_{c m} b A_{s 1} f_{y}} .
$$

The compressive stress of reinforcement can be calculated by applying Hooke's law: $\sigma_{s 2}=E_{s 2} \cdot \varepsilon_{s 2}$. But not higher than compressive reinforcement yield strength $\sigma_{s 2} \leq f_{s 2}$. Strains $\varepsilon_{s 2}$ can be found from Figure 11, using $h_{\text {cr.lim.d1 }}$ calculated by Eq. (17).

Comparison of estimated and experimental values of the limit crack depth is presented in Figure 12.

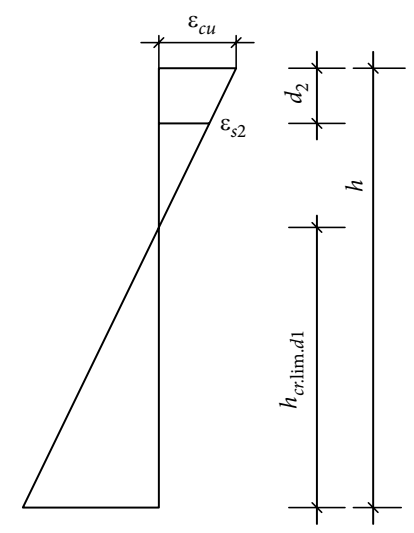

Fig. 11. State of strain at cross-section

a)

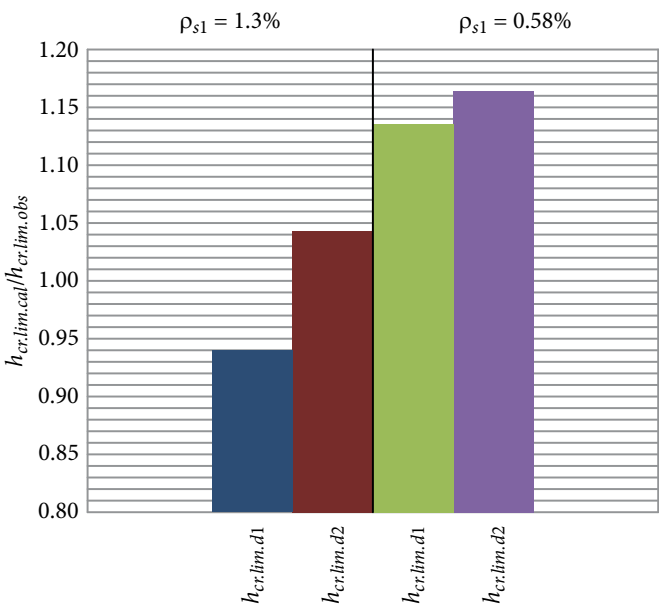

As we see from Figure 12a, the limit crack depth calculated by Eq. $(17,18)$ and determined experimentally differed by $4.33 \div 6.00 \%$, when reinforcement ratio $\rho_{s 1}=1.3 \%$. The values obtained by evaluating the compression zone reinforcement were more accurate, but bigger than those set experimentally. When reinforcement ratio $\rho_{s 1}=0.58 \%$ the difference became $13.59 \div 16.51 \%$. In this case, more precise values were set without compression zone reinforcement evaluation. However, the limit crack depth calculated by Eq. $(17,18)$ had better agreement to experimentally set final crack depth $h_{\text {cr.max.obs }}$, when beam's fracture moment $M_{u 2 . o b s}$ was reached (see Fig. 12b). The difference was $2.00 \div 12.00 \%$, when reinforcement ratio $\rho_{s 1}=$ $1.3 \%$, and $0.00 \div 3.00 \%$, when reinforcement ratio $\rho_{s 1}=$ $0.58 \%$. The values obtained by evaluating the compression zone reinforcement were more accurate.

\section{Conclusions}

1. In the assessment of existing buildings when reinforced concrete structure are being deflect it is important to determine the special attributes of the cross-section. Furthermore, the degree of remaining structure's bearing capacity reserve, between the reinforcement stress reaches yield strength and final structure's collapse, should be considered. Normal cross-section cracks in a construction are a consequence of the stress state. Here proposed calculation method with direct measurement of the compression zone height $\left(x \approx h-h_{c r}\right)$ allows to evaluate the behavior of reinforced concrete beams fracture sufficiently precisely.

b)

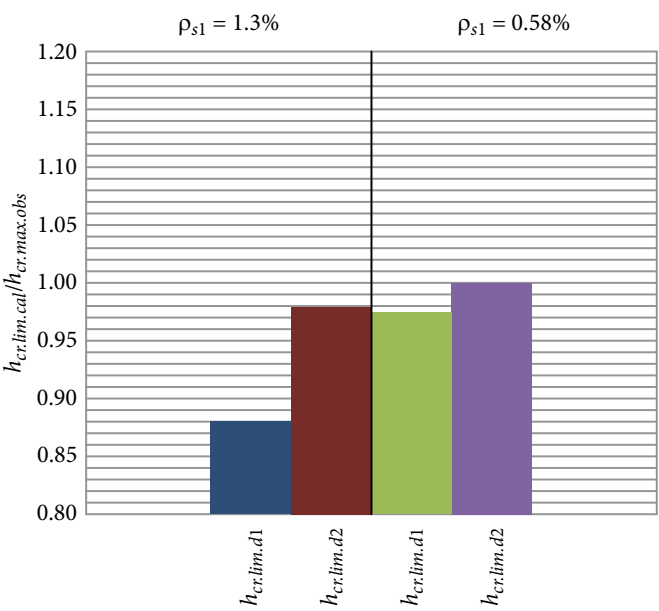

Fig. 12. Comparison of estimated and experimental values of the limit crack depth: $a$ ) the ratio of limit crack depth calculated by equations (17-18) and experimentally set limit crack depth $h_{c r . l i m . o b s}$, when reinforcement stress reached yield strength;

$b)$ the ratio of limit crack depth calculated by equations (17-18) and experimentally set final crack depth $h_{\text {cr.max.obs }}$, when beam's fracture moment $M_{u 2 . o b s}$ was reached 
2. The reserve between beam's tensile reinforcement yielding stress and final fracture got higher from $7 \%$ to $13 \%$, when decreasing the reinforcement ratio from 0.013 to 0.0058 . Such a difference was caused by beam's fracture consequence. Concrete crushed and reinforcement tensile strength was not reached when reinforcement ratio was $1.3 \%$. But when reinforcement ratio changed to $0.58 \%$ tensile reinforcement failed, it means that the full reinforcement stress reserve capacity (from yield to tensile strength) was employed. The values of $M_{u 1}$ calculated by expressions (1-10) were in a relatively good agreement with experimental results (see Fig. 9a) and final fracture moment $M_{u 2}$ calculated by Eq. (11) exactly corresponds to observed, the difference is only $0 \div 1 \%$ (see Fig. $9 b$ ).

3. The bending moment $M_{u 1 . d}$ calculation results $\left(\rho_{s 1}=0.58 \div 1.30 \%\right)$ confirmed that elastic deformations dominate in the concrete's compressive zone when tensile reinforcement stress reaches the yield strength and it is reasonable to use triangular concrete's compression zone chart, without tensile concrete evaluation above crack. There is a possibility to evaluate the flexural strength of reinforced concrete structures according to the limit crack depth in normal cross-section calculated by (17) or (18) equations.

\section{References}

ACI 318. Building Code Requirements for Structural Concrete (ACI 318-05) and Commentary (ACI 318R-05). ACI Committee. $430 \mathrm{p}$.

Atkočiūnas, J.; Čižas, A. E. 2009. Netamprių konstrukciju mechanika [Non-elastic structural mechanics]. Vilnius: Technika (in Lithuanian). https://doi.org/10.3846/1077-S

Dulinskas, E.; Zabulionis, D. 2007. Analysis of equivalent substitution of rectangular stress block for nonlinear stress diagram, Mechanika 6(68): 26-38.

Dulinskas, E.; Zabulionis, D.; Balevičius, R. 2007. On the equivalence of compressive concrete diagrams in analysis of flexural reinforced concrete elements, in 9th International Conference on Modern Building Materials, Structures and Techniques, 16-18 May 2007, Vilnius, Lithuania.

LST EN 1992-1-1:2005. Eurocode 2: Design of concrete structures - Part 1-1: General rules and rules for buildings. European standard.

Jokūbaitis, V.; Juknevičius, L. 2013. Critical depth of normal cracks in reinforced concrete beams of rectangular crosssection, Journal of Civil Engineering and Management 19(4): 583-590. https://doi.org/10.3846/13923730.2013.812575

Jokūbaitis, V.; Juknevičius, L.; Šalna, R. 2013. Conditions for failure of normal section in flexural reinforced concrete beams of rectangular cross-section, in 11th International Conference on Modern Building Materials, Structures and Techniques, 16-17 May 2013, Vilnius, Lithuania. https://doi.org/10.1016/j.proeng.2013.04.060

Michailov, K. V. 1977. Novoje o prochnosti zhelezobetona. Moskva: Stroijizdat (in Russian).

Narayanan, R. S.; Beeby, A. 2005. Designers' guide to EN1992-11 and En1992-1-2. Eurocode2: Design of concrete structures. General rules and rules for buildings and structural fire design. London: Thomas Telford.

Park, R.; Paulay, T. 1975. Reinforced concrete structures. Canada: John Wiley \& Sons. https://doi.org/10.1002/9780470172834

Rüsch, H. 1960. Research towards a general flexural theory for structural concrete, ACI Journal 57: 1-28.

Shafigh, P.; Hassanpour, M. M.; Razavi, S. V.; Kobraei, M. 2011. An investigation of the flexural behaviour of reinforced lightweight concrete beams, International Journal of Physical Sciences 6(10): 2414-2421.

Zabulionis, D.; Dulinskas, E. 2008. Analysis of compression zone parameters of cross-section in flexural reinforced concrete members according to EC2 and STR 2.05.05, Mechanika 3(71): 12-19.

Židonis, I. 2007a. A simple to integrate formula of stress as a function of strain in concrete and its description procedure, Mechanika 4(66): 23-30.

Židonis, I. 2007b. Method for calculation of stress-strain state parameters in normal sections of structural members, in 9th International Conference on Modern Building Materials, Structures and Techniques, 16-18 May 2007, Vilnius, Lithuania.

Židonis, I. 2010. Alternative method for calculation of stressstrain state parameters in cross-sections of beam type members, in 10th International Conference on Modern Building Materials, Structures and Techniques, 19-21 May 2010, Vilnius, Lithuania.

Justas SLAITAS is a first year PhD student at the Faculty of Civil Engineering, Department of Reinforced Concrete and Masonry Structures at Vilnius Gediminas Technical University. Research interests: the fracture of reinforced concrete structures.

Zbynek HLAVAC graduated with PhD title at Brno University of Technology, Faculty of Civil Engineering in 2011. Author of more than 30 publications. Currently working as senior researcher at Research Centre Rez Ltd. doing nuclear research under ÚJV Group.

Arnoldas ŠNEIDERIS. Assoc. Prof. Dr at the Department of Reinforced Concrete and Masonry Structures, Vilnius Gediminas Technical University. Research interests: evaluation of the existing reinforced concrete and masonry structures, evaluation of fire resistance to reinforced concrete and masonry structures. 